\title{
Eternity, Instantaneity, and Temporality
}

\author{
Tackling the Problem of Time in Plato's Cosmology
}

\author{
Silvia De Bianchi
}

\subsection{Introduction: Can Time Arise from Durationless Atemporality?}

In his 1974 work Time and the Timeless in Greek Thought, Kolb suggested a way of presenting the problem of temporality and atemporality in Plato that I do not find satisfactory in its implications and assumptions. The central problem analyzed by Kolb (1974) can be presented as follows: Plato must explain a transition from the Forms to concrete becoming in time, but, as Aristotle noticed (Metaphysics 991b10-993a10), this transition fails because any timeless happening only defines a mathematical pattern of order, but certainly not its application and effectiveness in the sensible world. ${ }^{1}$

In fact, Plato's concept of atemporality in turn is far richer than normally expected and a deeper analysis of the meaning of atemporality is needed, especially in reconstructing his cosmogony and cosmology. I claim that it is misleading to equate atemporality only with eternity ${ }^{2}$ and that there is more than one type of atemporality, i.e., timeless eternity and non-durational eternity. ${ }^{3}$

1 It is worth mentioning that Aristotle's criticism of the Pythagoreans was similar, in that for him they generated every pattern of order from the Unit and the Unlimited, and this generation was a temporal process involving spatialized units (see Metaph. 989b29-99oa32 and $1083 \mathrm{~b} 8-23$ ). In this contribution I try to show that things are more complex and that what Plato seemed to have in mind when grounding the generation is a special kind of atemporality, i.e. instantaneity.

2 Whittaker (1968) reconstructed how aei was used by Plotinus with reference to non-durational eternity and clarified that Plotinus and Proclus assumed that Plato used the term in this sense. However, Proclus' thesis, according to which Plato attributed a sense of non-durational eternity to aei, would not be substantiated. According to Whittaker, the notion of nondurational eternity was not a commonplace in Plato's day.

3 If we assume, in agreement with Cherniss $(1944,212)$ and Vlastos $(1965,379-99)$, that aion means non-duration with respect to the paradigm but duration when associated with time, eternity can thus certainly be determined as timeless eternity in opposition to temporality. However, it is perfectly possible to think of a durational eternity, an everlasting or unbounded eternity. Even if Plato is not discussing in the Timaeus the thesis that the Forms could be in time but unchanging, it is clear he thought that it was possible to think of durational and non-durational eternity. 
Furthermore, I claim that there is a way of defining atemporality independently from the meaning that we attribute to eternity and this type of atemporality is instantaneity. I argue that instantaneity, as a specific form of atemporality different from eternity, justifies atemporal transitions between opposite pairs of predicates attributed to the same subject by implying a sudden change or switch and lies behind any understanding of generation (to gignesthai). The problem of transition from opposites, e.g. Being or not Being is the oldest one in Greek thought and can be clearly identified in Parmenides' fragments (Fr. 8, 5-10). It did not simply regarded conceivability of something springing out of its opposite, but also the problem of effective generation. Therefore, regarding the problem of transition from atemporality to temporality, which is typical of Western cosmology, any cogent account of Plato's Timaues must inevitably lead to reject the idea that the generation of time is temporal, as for instance von Leyden (1964) argued. I suggest, in fact, that if temporality is generated from atemporality, this passage must rely on a ground that is not continuous; therefore, it is from non-durational atemporality that time emerges, but this non-durational atemporality is not eternity since what should be explained is precisely the transition from eternity to temporality in the generation of the physical world. In other words, in his cosmogonic account, Plato did not conflate atemporality with eternity, ${ }^{4}$ nor duration with time. ${ }^{5}$ On the contrary, Plato's Timaeus offers a far richer view of atemporality — at least, richer than ours - that also emerged in other dialogues and represents a fundamental improvement with respect to the Parmenidean picture.

Sattler (2019), for instance, suggested that Plato's Parmenides, in which the notion of exaiphnes is presented and discussed, can be seen as contributing to the development of temporal and spatial conceptualizations in ancient Greek thought. Even if Plato's Parmenides does not contain any explicit cosmological account, it discusses fundamental notions that play a relevant role in the Platonic cosmology and in the Timaeus, in particular.

Thus, to justify a transition from the Forms to the sensible world a more complex connotation of atemporality is needed and it includes at least the

4 For a discussion on eternity and temporality, see Sorabji 1983, 108-12 and Whittaker 1968.

5 However, the evidence from the Timaeus, as we shall see, is just that the parts of time possess duration, and not that time per se has a specific one. A particular interpretation of aiōn and diaionia $(\mathrm{Ti} .38 \mathrm{~b})$ can even suggest that time is non-durational, once we assume that its continuity is the result of the continuous, circular heavenly motion: its continuity could be an illusion, or a property "transferred" to it from a more complex process. In other words, the transition from atemporality to temporality is guaranteed by the fact that both the apparent continuity of time and the planetary motions are based on a unit that is out of temporality, a number. 
non-temporal notion of the exaiphnes, as well as an atemporal notion of eternity. Although the term 'exaiphnes' does not explicitly appear the Timaeus, it represents a useful tool for thinking of the transitions in the cosmogony, e.g. from pre-cosmos to cosmos, from atemporality to temporality and for enriching our understanding of the demiurgic agency and the function of the chöra.

In order to accomplish this task, I shall first investigate the link between Plato's strategy of portraying time as connected to planetary motion in the Timaeus and the toy models that he uses in other dialogues (sections 6.2 and 6.3) to show the relevance of his reflections on atemporality and instantaneity in the Parmenides (section 6.4) for the elaboration of his definition of time in the Timaeus. Then I will show the impact of Plato's notion of instantaneity on the definition and ontological functions of the Demiurge and the Receptacle (section 6.5).

\subsection{Fixing the Moving Image of Eternity}

Let us begin with one of the most commented upon passages of the Timaeus, to scrutinize some interpretations that can throw light on the interplay of temporality and atemporality in Plato's cosmogony and cosmology:

So as that pattern is the Living Being that is for ever existent, he sought to make this universe also like it, so far as might be, in that respect. on the generated thing. But he took thought to make, as it were, a moving likeness of eternity; and, at the same time that he ordered the Heaven, he made, of eternity that abides in unity, an everlasting likeness moving according to number - that to which we have given the name Time.

Timaeus $37 \mathrm{~d} 1-5^{6}$

This passage has been object of many interpretations for centuries, yet its meaning is far from clear. Recent contributions meant to clarify Plato's cosmology focused on the notions of aiōn and aidios, with emphasis on the meaning of aidios, "which applies not only to what simply is eternal, but also to what came to be but will not perish" (Thein 2020). However, to identify the exact meaning of these terms is not the only trouble associated with this passage. I want to draw attention on the expression "according to number" (kat'arithmon), which is ambiguous, and worth being analyzed if one wants to advance

6 Quotations from the Timaeus are taken from Cornford's (1952) translation. 
in the determination of the role of instantaneity in the Timaeus. Indeed, it can be interpreted in three ways, at least i.e. 1) "according to the notion of number in general"; 2) "according to the rules of numbers", or 3) "along the number series". ${ }^{7}$ There are three possible scenarios open at this point. In the first scenario, number means unit as a standard in general. In other words, this is nothing but a metaphor that helps us in thinking of the analogy between time and eternity or the likeness of the two through the concept of unit: both are units, but one is at rest and the other is moving. This allows us to grasp the operational function of time moving relative to something quiet and inert.

The second scenario is more interesting and can be connected to the second part of the abovementioned passage referring to the distinction of the parts of time:

For there were no days and nights, months and years, before the Heaven came into being; but he planned that they should now come to be at the same time that the Heaven was framed. All these are parts of Time, and 'was' and, 'shall be' are forms of time that have come to be; we are wrong to transfer them unthinkingly to eternal being. We say that it was and is and shall be; but 'is' alone really belongs to it and describes it truly; 'was' and 'shall be' are properly used of becoming which proceeds in time, for they are motions. But that which is for ever in the same state immovably cannot be becoming older or younger by lapse of time nor can it ever become so; neither can it now have been, nor will it be in the future; and in general nothing belongs to it of all that Becoming attaches to the moving things of sense; but these have come into being as forms of time, which images eternity and revolves according to number.

Timaeus 37e1-38a6

If we interpret the expression "according to number" as meaning "according to the laws or rules of numbers," then we have a clear reference to the foundations of mathematics being intrinsically connected to time:

7 Notice that in the fourth century вс, to associate time with the preposition kata was to designate a particular calendar. For instance, kata theon or kat'archonta were expressions used to designate events in time corresponding to an epoch rather than a year, in the first case according to the lunar calendar and in the second to the Prytany calendar; see Pritchett and Van der Waerden $(1961,21)$ and discussion below in this section. The third option according to which one renders kata + acc. in a distributive manner is more plausible because it accounts for the term arithmos used in singular to be contrasted to arithmoi in plural that does not appear in this important passage. 
There will always be an $n$ greater than, equal to, or less than $\mathrm{X}$.

According to this simple, fundamental rule, one can divide time into portions or units responding to past (less than), present (equal to), and future (greater than); albeit arbitrary, these distinctions respond to universal rules and are grounded in the analogy between number series and time series. In particular, the lunar calendar used in Attica during Plato's time responds to this rule, as shown by Hannah $(2005,42-70){ }^{8}$ According to the lunar calendar the year, as well as each month, started with New Moon or Noumenia, the tenth day as the tenth of the month waxing, the twentieth as the earlier tenth, the twenty-first day of the month was named "later tenth" and the day before the New Moon was called "Old New Moon."9 The lunar calendar included ten months in a year, leading to a maximum of 304 days (see Allen 1947, 164) and was therefore subject to adjustments that could lead to its harmonization with seasons and thus with the solar calendar and the Prytany calendar, which counted dates according to the ten Prytanies of each assembly, containing 366 days (months onesix, made up of thirty-seven days, and months seven-ten, made up of thirty-six days). Both the lunar and Prytany calendars had only ten months (see Pritchett and Van der Waerden 1961, 18-19). ${ }^{10}$ Furthermore, we know that in between

8 See also in the present volume, Chapter 5 , section 5.2.

9 Notice that the Eleusinian Mysteries started being celebrated on the Old New Moon day and were adopting a lunar calendar.

10 See Pritchett and Van der Waerden (1961, 26-27). They suggest that the existence of an observational calendar for a very early period is proved by the terminology used by the Athenians to designate the days. They called the first day "new moon day" and the days from the first to the tenth (inclusive) they invariably referred to as "days of the waxing moon." The days from the twenty-first through the twenty-ninth were called the "days of the waning moon." The calendar had an empirical and observational basis, it was tied to the phases of the moon, and expressed the days in terms of these phases. In the period of Solon, Diogenes Laertius (1.59) reports that the Athenians had "to observe the days according to the moon." Plutarch, Solon 25 (Perrin 1914) reported: "Observing the irregularity of the month, and that the motion of the moon does not always coincide with the rising and setting of the sun, but that often she overtakes and passes the sun on the same day, he [Solon] ordered that day to be called the Old and New, assigning the portion of it which preceded the conjunction to the expiring month, and the remaining portion to the month that was just beginning. He [Solon] was thus the first, as it would seem, to understand Homer's verse, which speaks of a day when 'This month is waning, and the next is setting in,' and the day following this he called the first of the month. After the twentieth he did not count the days by adding them to twenty, but by subtracting them from thirty, on a descending scale, like the waning of the moon." In the fifth century вс, Aristophanes (Nubes line 626), makes reference to the fact that the untampered calendar was "according to the moon". Finally, in Aristotle (Ath. Pol. 43.2), we find a statement showing that in 
Solon's government and Aristotle's works, the lunar calendar was endorsed in Attica (Pritchett and Van der Waerden 1961, 27), something that fits nicely with the opening of the dialogue in which Timaeus narrates the story of Solon's trip to Egypt and mentions its importance for the social and political life of Athens.

The third scenario, which derives from interpreting the expression kat'arithmon as "along the number series, or along the all of number" leads to the following interpretation of the passage: time, understood as unit mirrors eternity which abides in unity, but in contrast it also moves along the number series, assuming different values at different points and this motion generates further divisions of time itself and the cosmic cycles can be counted because a specific position of the planets can be associated to each unit of time and to a number that correspond to that position at a specific point of time. It must be noticed here that this scenario responds to the need of representing the sameness, i.e. the unity in the multiplicity, i.e. the number series, and therefore to the need of embodying in the physical world the Form of the Same and the Different that the Demiurge uses to forge the sphere of the World Soul. By adding to this the previous remarks on the type of lunar calendar used in Attica and considering the relevance of Pythagorean doctrines for calculating sidereal cycles and seasons, it is not implausible to assert that the passage in $T i$. $37 \mathrm{~d}$ is clearly multi-layered and that there is room for the co-presence of more possible scenarios. ${ }^{11}$ As Finamore and Dillon $(2002,362)$ emphasize, we find in Iamblichus'

the fourth century the Athenians regulated the calendar by the moon, meaning that each archon's year began with a new moon.

11 A fourth possible scenario could be generated by reading kat'arithmon as "according to a specific number" and in interpreting it as being the Decad, thereby tending to endorse an exegesis of the passage in Ti. 37d as connected to the Pythagorean tenet that the Decad contains in itself all the laws of numbers (scenario two) and was also considered the supreme unit of the world, being the condition of all number series (scenario one and three). However, to equate Plato's late theory of numbers and Pythagorean doctrines is problematic, but if one endorses the proposal to translate kat'arithmon with "along the all of number" or "along all of number series", this is not at odd with the translation of the term aiōn which could be interpreted as the Eon, the number ten. See Iamblichus, Theologumena Arithmeticae 79-87. See also Brisson (2012, 43-44), translating Iamblichus: "The Pythagoreans also always assimilated mathematical knowledge, in absolutely all cases and in each in particular, to true beings, to all the gods, to the dispositions and powers of the soul, to the celestial phenomena and the orbits of the stars, to all the elements of bodies in becoming and the things that are composed from these elements, and to matter and all things that come to be from it, taking their proper images with regard to each of these beings, both all of them in general and from each one. They traced mathematical objects back to the genuine beings, either because they have the same account in common, or through a dim impression, or because of a resemblance, very close or very distant, or because images feature a resemblance with their model, or because the model plays the role of cause that precedes its effect, as is the case for a 
Commentary on the Timaeus, fr. 29 and fr. 64 the reading of aionn as eternity and as Eon. Iamblichus associated eternity with properties such as uniformity, infinity, simultaneity, and permanent presentness. Thus, the passage in Ti. $37 \mathrm{~d}$ would assume a specific meaning according to which the planetary motions tend to imitate the perfection of eternity by means of a periodicity that is given by their relative positions and their values are always contained in the number series and therefore in number ten. The interpretation of aiōn as deeply related to the Decad is an old and important one, but by no means it implies to read the whole dialogue through the lenses of Pythagorean doctrines. ${ }^{12}$

For the time being, I tend to consider the expression kat'artihmon without meaning if not further determined with respect to the expressions en eni and iousan. Therefore, I am inclined to render it with "along the number series" in contrast with the fact that eternity abides in the One or in unity, since it correctly describes at least the transient character of time flow. Furthermore, to generate temporality also means to inject teleology into the physical world, e.g., no task can be accomplished in eternity, because it is already there and achieved in a permanent presentness. If eternity is understood, as Iamblichus suggested, as the Monad or the One, then it is worth comparing Plato's view of atemporality in the Timaeus with the perspective presented in the Parmenides because it is clear that the problem of the transition from the eternal world of Forms to the physical one can be overcome to a certain extent with the intervention of the demiurgic agency and with the shaping of the World Soul, but still the metaphysical problem of the foundations of the transition from atemporality to temporality is far from being solved.

However, before moving on to this in the next section, I want to draw attention to a subtle consequence in assuming a certain reading of the expression kat'arithmon as related to Plato's late theory of numbers. Within this picture, time and its parts must derive from the properties of number series through an analogy with change and motion; namely, a unit of time itself is something fixed, it is like an icon, a sacred statue, or, if one wishes, a clock hand that moves around in a circle without deformation or translation. It flows or moves due to a circular motion, by using one of its extremes as a pivot. If we take

model, or in still some other way. They couple mathematical objects to things in several other ways as well, since things can be assimilated to mathematical objects, and mathematical objects can by nature be likened to things, both being in a relation of mutual resemblance."

12 For Aristotle attribution of the doctrine of the Decad to the late Plato and the early Academy, see Arist. De an. 404b19-24 = De philos. fr. 11 Ross. See also Zhmud (2013, 328-330). 
seriously the definition of time provided in the Timaeus, we also detect the need of visualizing and materializing temporality and the universal rules that drive the cosmos, planetary motions, and determine their positions: "To tell all this without using visible models would be a labor spent in vain" (Timaeus 4od1-3). As Cornford (1952, 74) and McHugh (2019, 168) have underlined, a reference to an armillary sphere is highly probable, considering that they had been in use in ancient Greece since Thales' time, including those of Eudoxus of Cnidus. Their functions, however, remain unclear, even if recent studies, such as Freeth, Higgon, Decanalis, MacDonald, Georgakopoulou \& Wojcik (2021) throw light on the underlying mechanism and cosmological assumptions. ${ }^{13}$

Whereas the later Archimedes' sphere was certainly based on a sophisticated mechanism reproducing the periodicity of planetary motions and those motions relative to stars, it is more difficult to assess whether and which armillary sphere Plato had in mind. Furthermore, Cicero already suggested this reading of the passage, in De republica I, 14 and De natura deorum II, 34 with reference to the Second Letter (312d), in which the armillary sphere of Syracuse is mentioned (see also Cornford 1952, 73-75). Even if the letter is considered spurious, albeit of extreme importance, ${ }^{14}$ what counts is that it was considered plausible to talk about the presence of an armillary sphere held in Syracuse during Plato's time. Robert Hannah suggests an explicit link between this type of armillary sphere and Plato's Timaeus (see Hannah 2017, 89-9o), thereby fostering the idea that Eudoxus of Cnidus, among other successors, was seeking to embody in an orrery the cosmology and astronomy devised in Plato's Timaeus (see Gregory 2000, 183). The existence of the Antikythera mechanism and the recent discovery of its functioning based on Plato's cosmology and Babylonian calendars corroborates this hypothesis.

Kalligas (2016), for instance, offers a cogent account reconstructing the type of spheres known in Plato's time. There are hints not only in Plato's Republic (616c-617a-b), but also in other dialogues that support Gregory's and Kalligas' reading. Indeed, the simplified image of the world by means of an orrery is present in the Statesman at 270a, in which the Stranger introduces the discourse on the myth of the golden age of Chronos, when the God suddenly

13 They may have been orreries with an educational purpose, but not intended for the general public, more probably, in a similar way as to the Antikythera Mechanism, they were tools for simplifying and calculating the relative positions of the planets and stars, or they may simply have been toy models designed to inspire further research in astrology (see Kalligas 2016).

See for instance the discussion in Bluck 196o. 
turned the motion of the sun in the opposite direction. ${ }^{15}$ The passages in the Republic (616c-617b) and the Statesman (269d-270a) imply phenomena, e.g. the sudden spin flip of axial rotation, that can be exemplified by a mechanical model or an orrery. It is worth noting that in the Statesman, Plato admits that the order of time can be reversed in the physical world and that the order of processes in the sensible world depends on the direction of time flow. Just as if the world could be embodied by an orrery, and an agent could decide to flip the spin of the axial rotation or the revolution of a planet represented by a sphere.

It is very intriguing to establish a comparison between the Statesman and the Timaeus with respect to the way in which the role of divine demiurgic agency is portrayed and how it affects the representation of temporality and its properties, such as time direction or continuity. What is, however, immutable is the intrinsic link between temporality and physical world, i.e., their simultaneous generation. If we stick to a literal interpretation of the Timaeus, we must conclude that the ground of the generation of both the heavens and time is out of time. The problem is that this generation cannot "happen" in an eternal presentness. The passages in the Statesman help us in suggesting that the sudden switch of the direction of motion of the Sun can be made conceptually cogent, thanks to the notion of instantaneity rather than temporality. ${ }^{16} \mathrm{To}$ assess whether this hypothesis could be correct, I shall devote the next two sections to the notion of atemporality, relevant for Plato's cosmogony and cosmology in the Timaeus and the Parmenides, respectively.

\subsection{On Generation of Time and the World}

On the grounds of the passages on time and cosmology present in both the Statesman and the Timaeus, it is worth investigating the implications of the hypothesis that Plato had in mind toy models and orreries not just meant to calculate celestial events but also as symbols helping to visualize the implications of a higher metaphysical order, when approaching the cosmological discourse and the generation of time. The first and most important implication is the central tenet that there cannot be time without the sensible world and vice versa, otherwise the result would be useless, meaningless, and absurd, like

\footnotetext{
15 See Brisson 2000, $176 \mathrm{ff}$. The same myth is present in Euripides, Orestes 986 and Electra 734, as well as in Herodotus (II, 142).

16 On the different types of change and continuous substantial change, see Sedley (2007, $103)$ and the discussion in Johansen $(2008 ; 2014,301)$.
} 
having a clock without a moving clock hand or a stick (like a gnomon) without a background divided in units that works as a frame of reference:

Be that as it may, Time came into being together with the Heaven, in order that, as they were brought into being together, so they may be dissolved together, if ever their dissolution should come to pass; and it is made after the pattern of the ever-enduring nature, in order that it may be as like that pattern as possible; for the pattern is a thing that has being for all eternity, whereas the Heaven has been and is and shall be perpetually throughout all time.

Timaeus 38b1-c2

In Plato's time, the clock was a gnomon projecting shadows (stoicheia) on the ground. The stick was fixed, and the projected shadow changed position during the day following the motion of the sun. Now, the interesting aspect of these passages on the generation of time is that we find an apparent conflict between eternity and temporality, i.e., one is at rest and the other moving. However, time's motion is only apparent, because in itself time is both at rest and in motion. This contradiction is an illusion insofar as one distinguishes between relative and absolute motion (Timaeus $38 \mathrm{e}-39 \mathrm{a}$ ) and assumes a metaphysical and ontological distinction between temporality and eternity. Eternity pertains to an ontological level that is not ours; it is not perceptible, but we can limit its image according to a selection of units in the number series and we organize life on its grounds, e.g., agricultural cycles that in turn respect the cosmic order of planets as a hymn to life. ${ }^{17}$ The term aion in Homer means "spinal cord, place of life," and only as a secondary option can it be translated as "duration of life." Nevertheless, whichever meaning we attribute to aiōn, be it eternity or the Monad, what counts is the fact that it is unique. Time in turn is always divisible, whereas eternity is not; temporality can be perceivable and quantifiable as a way of being of sensible things, whereas eternity is not. Time can be made perceivable thanks to planets, stars, and their motions as if they

17 However, Plato uses terminology that emphasizes the optical imperceptibility of eternity, the impossibility of it being geometrized. This is not the case for its acoustic imperceptibility (think of Pythagoras' legendary capacity to hear the harmony of the sun). An example of the co-presence of intelligible imperceptibility and sensible perception is given by the very same structure of the universe. The celestial vault of fixed stars rotates upon itself but does not change its position and conserves the relative positions: this periodicity of the motion of the fixed stars is common to both the celestial vault and the acoustic waves. For this reason, music is a valid means through which order, regularity, and a principle of conservation can be imposed on the world (see Ti. $47 \mathrm{c}-\mathrm{d}$ ). 
could be used as an orrery, eternity cannot be directly represented by means of the latter. Furthermore, the celestial vault is organized according to mathematical proportions in order to let animals and living beings learn arithmetic. It is as if we could live immersed in a gigantic orrery that teaches us the ultimate truths of life and numbers:

And in order that there might be a conspicuous measure for the relative speed and slowness with which they moved in their eight revolutions, the god kindled a light in the second orbit from the Earth — what we now call the Sun -in order that he might fill the whole heaven with his shining and that all living things for whom it was meet might possess number, learning it from the revolution of the Same and uniform.

Timaeus 39b1-5

Planets and stars are indeed instruments of time, being at once generated and constituting time by preserving the perfect number of time (arithmos chronou), through which it accomplishes its proper scope:

In virtue, then, of this plan and intent of the god for the birth of Time, in order that Time might be brought into being, Sun and Moon and five other stars - 'wanderers', as they are called - were made to define and preserve the numbers of Time. Having made a body for each of them, the god set them in the circuits in which the revolution of the Different was moving in seven circuits seven bodies: the Moon in the circle nearest the Earth; the Sun in the second above the Earth; the Morning Star (Venus) and the one called sacred to Hermes (Mercury) in circles revolving so as, in point of speed, to run their race with the Sun, but possessing the power contrary to his; whereby the Sun and the star of Hermes and the Morning Star alike overtake and are overtaken by one another.

Timaeus $38 \mathrm{c} 1-\mathrm{d} 4$

It is worth noticing here that it is the absolute circular motion of the celestial vault of fixed stars that starts first and creates time, but this vault is not the world. The world includes other stars and planets, and the beginning of their motions coincides with the moment in which time comes into being. However, Timaeus remarks that human beings are far from appreciating the perfection of the gigantic orrery, being yet unable to measure all relative motions of planets and stars as well as their synchronization with the motion of the same of 
the celestial vault of fixed stars that occurs in the perfect year. ${ }^{18}$ What emerges from the text is the idea that the mirroring and imitation of the paradigm's perfection is explicit when the analogy between the universe and the Living Thing is before the eyes of observers. Therefore, the perfection of time as the image of eternity can be witnessed only through its organa, i.e., the heavenly bodies, their motions and beautiful disposition. We are now ready to advance the reflection upon the double meaning of time in the dialogue:

(a) It can be a cyclic unity or a continuum to be divided.

(b) It can be something susceptible to an operational definition (time made objective, measurable).

Furthermore, in the Timaeus, the present has a double connotation, in that past, present, and future are referred to language, namely to the way in which we use time as a parameter or scalar to describe the world and its processes, yet in reality the unit measure of the eternal truth is the "Now" (nyn) as presentness (Parmenides 152e1-3). Therefore, the Now is different from time; it cannot be part of it. I can identify different "Nows" in time, by arbitrarily dividing it, but I cannot say that time per se is made of "Nows."

The Now is presented as something ontologically different from time, but it is also different from the instant (exaiphnes). Thus, whereas the term chronos is undoubtedly connoting temporality, the concepts of myn and exaiphnes pertain to atemporality. Indeed, the notion of nun is different from the present in that it is also not a part of time, but it can be eternal present when referring to eternity. Purely atemporal is the instant. Plato never portrayed the instant as a part or portion of time and clearly distinguished it from the "Now," whereas Aristotle started to conflate the two, exerting a millennial hegemony over this deeper way of portraying atemporality.

18 The main passage supporting my view reads: "Thus and for these reasons day and night came into being, the period of the single and most intelligent revolution gone round his own circle. The periods of the rest have not been observed by men, save for a few; and men have no names for them, nor do they measure one against another by numerical reckoning. They barely know that the wanderings of these others are time at all, bewildering as they are in number and of surprisingly intricate pattern. None the less it is possible to grasp that the perfect number of time (arithmos chronou) fulfils the perfect year at the moment when the relative speeds of all the eight revolutions have accomplished their courses together and reached their consummation, as measured by the circle of the Same and uniformly moving. In this way, then, and for these ends were brought into being all those stars that have turnings on their journey through the Heaven; in order that this world may be as like as possible to the perfect and intelligible Living Creature, in respect of imitating its ever-enduring nature" (Ti. 39c1-e2). 


\subsection{Instantaneity as a Form of Atemporality}

In agreement with Whittaker (1968) and Sattler (2019) I tend to read the passage at Timaeus $37 \mathrm{c}-38 \mathrm{c}$ as deeply connected with ideas discussed at Parmenides $140 \mathrm{o}-142 \mathrm{a}$ and $151 \mathrm{e}$ ff., I want to show that it is precisely by considering passages from Parmenides 151e ff. that the contrast between aiōn and chronos becomes perspicuous, and also that the exegesis of Plato's text brings us back a far richer view of atemporality. This section focuses on Plato's view of the instant (exaiphnes) as presented at Parmenides $156 \mathrm{~d}-157 \mathrm{~b}$. In it appears the relevant tenet according to which the Being and the Becoming of the One can be determined through the transition from one state to another or from affections (pathèmata) or properties to other affections and properties by means of the durationless instant. ${ }^{19}$

Whereas in the Parmenides $\left(155^{\mathrm{c} 8} 8-155 \mathrm{~d} 4\right)$, attention is mainly devoted to the implications of temporal relations (present, past, and future) with the One, at Parmenides $156 \mathrm{~d}-157 \mathrm{~b}$ we are dealing with an argument for the justification of operating a transition from one predicate to another in time. The grounds for this transition are not to be found in something that is in time or susceptible to temporal determination. This condition must be found "out of time," in the instantaneity.

The instant is situated in between Being and Becoming and is a necessary tool for determining the properties of the One with respect to Being. In my view, Plato's arguments point to the fact that there must be some grounds for any transition (155e-156c6), namely a perspective through which we can account for any sudden transition or non-local switching from one state to another, as well as for the possibility of thinking of opposite predicates within the same discourse and without contradiction. Any condition of a transition of the One, e.g., from one to many, occurs out of time, in the instant, but in turn the instant is the signature of a process of generation or signifies a transition in the physical world that occurs in time. Consider the following passage in which Socrates introduces the problem:

'And will the case not be the same in relation to other changes?' 'When it changes from being to destruction [157a] or from not being to becoming, does it not pass into an intermediate stage between certain forms of motion and rest, so that it neither is nor is not, neither comes into being nor is destroyed?' 
'Yes, so it appears.'

'And on the same principle, when it passes from one to many or from many to one, it is neither one nor many, is neither in a process of separation nor in one of combination. And in passing from like to unlike or from unlike to like, it is neither like nor unlike, neither in a process of assimilation nor in one of dissimilation; [157b] and in passing from small to great and to equal and vice versa, it is neither small nor great nor equal, neither in a process of increase, nor of diminution, nor of equality.'

'Apparently not.'

'All this, then, would happen to the one, if the one exists.'

'Yes, certainly.'

Parmenides $156 \mathrm{e}-157 \mathrm{~b}$

According to my reading, Plato's view of transition as being grounded on instantaneity is meant to give a definition of generation (to gignesthai) and provide a solid foundation for the notion of coming into being and the genesis of new states (Parmenides $156 \mathrm{e} 7-157 \mathrm{~b} 5$ ). Thus, in my view, in these passages Plato approaches the problem of justifying generation by means of instantaneity, which has a hybrid status: it only explains the possibility and actuality of generation, but it does not deal with the specific products of this generation. Plato's notion of the instant relies on the notion of the metaxu precisely because what justifies a transition cannot define the instant through time, whereas the instant signifies the non-place (to atopon) where any generation takes place. In this respect it brings with it a sense of absurdity, as famously mentioned in the dialogue. ${ }^{20}$ Among the most interesting properties of the instant is non-locality. Indeed, the instant as sudden shift or switch allows us to think of the interruption of a process and the conditions under which a new, different one may arise at any place or nowhere. Furthermore, given the atemporal character of the instant, understood in terms of a durationless thing, a state can pertain to an entity at once, or multiple states as actual possibilities can pertain to one and the same entity at once.

It is only thanks to the temporal dimension or "being in time" of the One that we can apply the principles of identity and of the excluded middle, but in the instant, they seem not to hold. This is the case when one wants to think of two opposite predicates at the same time, e.g., mortal and immortal

20 Cornelli $(2010,46)$ stresses the fundamental role of the metaxu in the Philebus: "Per Platone è propriamente quello che sta in mezzo ciò che si presenta come decisivo per la comprensione del mondo. Gli esempi delle lettere dell'alfabeto e della musica non lasciano dubbi sul primato del metaxu al riguardo." 
or "in motion" and "at rest," without contradiction. Plato's view of transition will consider opposed concepts, e.g., the pair positive/negative, mortal/ immortal, by simply enabling the determination of these pairs out of time. Furthermore, this view of transition is meant to consider pairs of opposite concepts, e.g., finite/infinite, living/dead, by leaving room for investigating intermediate stages of these opposite pairs in the continuum of the sensory world. When it is regarded as the result of a continuous process, a transition is referring to physical or mental states of the sensory world. The notion of the instant is what justifies the transition from one state to another or a sudden change of regime (switch, sudden change of direction of a motion), both in the external, physical world and in our bodies (e.g., the transition from pleasure to pain).

The assumption of instantaneity and the durationless is needed to preserve the variety of relationships that involve the partaking of the One in other Forms, but the ontological grounds for a transition from the world of Forms to the physical world passes through an assumption of instantaneity and the metaxu. This must occur because, together with the physical world, time is generated, in Plato's view, and this generation must follow from something different to temporality, but different to eternity as well. In this sense there is an indirect connection between eternity and spatio-temporal things, mediated by the instant. The instant looks like a sort of differentiating function or condition for thinking of the transition in the physical (temporal) world and, moreover, in continuous terms. However, there can be another type of transition that is non-local and defines the way in which change can occur in the One, i.e., how its properties can be configured when it partakes of the Being. The instant is again the main actor here; it is the condition for this second type of transition. Indeed, at the most abstract level of Plato's view of transition, the instant also allows him to characterize the inner determinations of the One at once and how it partakes of Being and Becoming without contradiction. This hybrid notion of transition, however, does not lead to the further determination of the properties of the One, but (as in the case of the justification for the transition in the physical world) it is simply a condition for it to take place. From what has been said so far, one can draw important consequences for the interpretation of the pre-cosmic state's representation in the Timaeus. In my view, only a specific view of transition and its grounding could coherently explain the passage from the eternity of the Forms and the sempiternal dimension of the soul to the temporal world. Indeed, instantaneity allows the compresence of Intellect, Soul, and world in the act of generation. The interaction between the three has been portrayed in paradoxical terms by Brisson $(2016,49)$, but as 
soon as one admits the role played by instantaneity in grounding any transition, difficulties can be overcome. ${ }^{21}$

\subsection{Instantaneity and the Cosmology in the Timaeus}

At this point in the discussion, we can go back to the Timaeus and look at three fundamental questions from a fresh perspective. There are at least three conceptual issues, which are beset by extreme difficulties and represent the subjects of a vast body of literature, that I would like to discuss in what follows. I am not pretending to resolve every obstacle in this article, but I want to reach the goal of showing how the concept of instantaneity offers a stronger and more solid interpretation for understanding Plato's cosmology. Difficulties in interpreting the Timaeus are associated with (a) the idea of the generation of time (Timaeus 37d), (b) the transient character of the chora, and c) the prototemporal dimension in which the demiurgic agency takes place. I suggest that one possible way to overcome these difficulties is to consider the role played by a specific type of atemporality, i.e., instantaneity. In order to look at the problem of the genesis of time, consider the following points.

According to the passage at Timaeus $37 \mathrm{~d}$, the generation of temporality presupposes its opposite, i.e., atemporality, and since there is no time unless planets are set into motion, there is an intermediate step to consider, which is where the transition from eternity to temporality and the proper generation of time takes place. This transition is known only indirectly, through symbol or metaphor, i.e., the moving image of eternity, but ontologically speaking it is made possible thanks to an intermediate stage, the metaxu, in which the Demiurge operates according to the Forms of the Same and the Different, the laws of numbers and harmonics that shape the world and give it a spherical form. These "operations" happen all at once, in the instant. Indeed, only in the instant can both identity and difference coexist without contradiction.

21 See Brisson (2016, 49): "In the Intellect, all knowledge is simultaneous and immediate, whereas in the Soul, there is change (metábasis) from one element to another, with the reasoning process moving from premise to conclusion. The Intellect is characterized by eternity, whereas the Soul is associated with time, which is engendered simultaneously with the soul: a paradoxical situation, insofar as like the Intellect, the Soul is an eternal reality. The Soul contains in succession and partition all that is found in a simultaneous and compact way in the Intellect, which Plotinus expresses by speaking of "reasons" (lógoi) which, in the soul, are equivalent to the Forms." 
Furthermore, at this stage, motion does not appear. Projections are not proper physical motions but geometrical operations that the Demiurge performs in the metaxu. Only when the complete determination of the structure of the fixed stars is ready can the sphere rotate upon itself: it moves and is always the same because it does not change place and does so at once. Planets and other celestial bodies in its interior start co-moving with respect to both each other and the system of fixed stars (the boundary of the sphere), thereby effectively generating the flow of time, but also setting themselves in time, and they do so at once. Therefore, there is no doubt that the kind of time described in the Timaeus is relational. It has an operational definition because it is used to measure the planetary motions, but from a metaphysical perspective, it is by no means absolute, being the result of co-moving reference frames, i.e., the sphere of fixed stars and the orthogonal plane of planetary orbits. ${ }^{22}$

\subsubsection{Atemporality and Demiurgic Agency: Acting at the Boundary}

This interpretation naturally leads to the third point that represents a conceptual difficulty in the Timaeus, namely the proto-temporal dimension from which the Demiurge's agency exerts its power. Consider the following passage:

Now it was not, nor can it ever be, permitted that the work of the supremely good should be anything but that which is best. Taking thought, therefore, he found that, among things that are by nature visible, no work that is without intelligence will ever be better than one that has intelligence, when each is taken as a whole, and moreover that intelligence cannot be present in anything apart from soul. In virtue of this reasoning, when he framed the universe, he fashioned reason within soul and soul within body, to the end that the work he accomplished might be by nature as excellent and perfect as possible. This, then, is how we must say, according to the likely account, that this world came to be, by the god's providence, in very truth a living creature with soul and reason. This being premised, we have now to state what follows next: What was the living creature in whose likeness he framed the world? We must not suppose that it was any creature that ranks only as a species; for no copy of that which is incomplete can ever be good. Let us rather say that the world is like, above all things, to that Living Creature of which all other living creatures, severally and in their families, are parts.

Timaeus 3oa4-c4

22 It would be extremely interesting to explore the idea that the plane of the planetary orbits could work as a sort of imaginary time in Plato's cosmology. 
What is extremely interesting is the proto-temporal and proto-motive function of the Demiurge's agency. What Timaeus describes is an agency that orders the motion of the world. He is out of time but also in a dimension suspended from and not only comprehended within eternity, because he must look at the eternity as a paradigm and must be out of it to imitate it. ${ }^{23}$ This interpretation is coherent with the idea that the Demiurge cannot act directly in the physical world, but only though the World Soul embodying the principles that he selected, and the elements that are also contained as shadows in the chöra.

The Demiurge must act in some way at the border of the world or from the boundary of the sphere, therefore, in the instant, in the metaxu. The proof that he cannot directly act upon the physical world is that he has to teach his "children" how to perform the mixing of elements (Timaeus 42e-43a). Thus, it is often asked, "Where does the Demiurge come from?" or, "Where does the Demiurge go after generating the world?" The answer, in my view is: everywhere and nowhere. He comes from, is, and rests in the metaxu. Therefore, his agency is of a special kind: it is an agency able to generate a perfect product, i.e., the best of all possible worlds, but one that is temporal, in the sense that it has a beginning (it could not be beautiful if infinite with respect to its origin, see Timaeus 28a-b) and possesses a measurable duration even if it can endure forever. Indeed, there is a powerful religious message emerging from this assumption: the world would be finite and subject to death and decomposition, but it continues, only because the Demiurge acts teleologically in order to preserve it. We are given the possibility of being perfectible, and our souls the chance to return to our stars (Timaeus 41e), in order to complete the most perfect masterpiece of all possible worlds, the only and most beautiful selfmoving image of life according to the laws of numbers and harmonics: this universe. This means that at the end of the cycle of reincarnations, all our souls being returned to the pre-assigned star fixed on the celestial vault, each soul will be identical with the place (situs) on the spherical surface and will partake in the only possible, globally symmetrical motion left to the world: the uniform, circular motion of the three-dimensional sphere of the world.

Thus, the cosmos will partake in the perfection of eternity, it will still possess three-dimensionality, therefore the elements of fire, earth, air, and water will constitute its bonds, yet, being different from both eternity and the third kind, i.e., the chōra, the world will be like an enduring Living Thing, a sort of gigantic animal, and it will be in apparent motion only-it will also be at rest, 
since it will not change its place (situs), being one and the same with the World Soul. The demiurgic agency ensures the presence of beauty and equilibrium in the cosmos and his will ensures the world does not perish and lets living beings accomplish their cycles of reincarnation (92c; see also 41e). To sum up, the Demiurge must be in the metaxu because it is from the atemporal dimension that he can design different worlds, e.g., two-dimensional rather than threedimensional (31a; $32 a-b)$ and in order to ensure a mixing of opposites, he must act out of eternity, but in the instant, i.e., out of the synchronic beginning of planetary motion and time series.

\subsubsection{Plato's Chōra and Instantaneity}

I would like now to discuss the consequences of reinterpreting temporality in the Timaeus, by showing the relevance of instantaneity for the understanding of the chorra. According to Sallis, the second beginning described in the dialogue is made "precisely in order to launch another discourse, a different one capable of being extended to that which remained outside Timaeus' first discourse" (Sallis 1999, 96). It is, then, for the purpose of completeness that Timaeus speaks of fire, air, water, and earth as they were before the generation of the heavens, and he appeals to the chöra as having a key role in the constitution of the world. I will not discuss what the chöra is in detail, because this would require an entirely new chapter, but I can point out the characteristics that are compatible with the idea that the metaxu is playing a fundamental role in enabling a transition from the four elements to the sensible world:

Our new starting-point in describing the universe must, however, be a fuller classification than we made before. We then distinguished two things; but now a third must be pointed out. For our earlier discourse the two were sufficient: one postulated as model, intelligible and always unchangingly real; second, a copy of this model, which becomes and is visible. A third we did not then distinguish, thinking that the two would suffice; but now, it seems, the argument compels us to attempt to bring to light and describe a form difficult and obscure. What nature must we, then, conceive it to possess and what part does it play? This, more than anything else: that it is the Receptacle-as it were, the nurse-of all Becoming.

Timaeus 48e1-49a5

The status of the chorra in the Timaeus is ambiguous, but at the same time coherent with the notion of metaxu. The chöra is in between the model and the sensible, empirical world insofar as it is in between Being and Becoming. 
This characteristic of being in motion and at rest at the same time is common to both the Receptacle and the World Soul: the chöra shakes itself but does not change place (situs). A perfect image of this is offered by ancient Greek agriculture and by the image Plato uses, the metaphor of the winnowing basket (Timaeus 52e6-7): the basket is shaken to separate the wheat from the chaff, thanks to the action of the wind. ${ }^{24}$ The basket is shaken in a vertical motion, up and down, but farmers were always able to pick it up at the same point, thereby ensuring equilibrium in system and periodicity. To the chorra we can attribute two contrary qualities at once: being in motion and at rest. Again, the careful reader will notice that this is the language of instantaneity, at least in a Platonic sense. Furthermore, the chöra also contains contrary qualities that contradict each other. Indeed, it would be impossible to think of contrary qualities if not in a temporal series, but in the chöra they can coexist. i.e., all elements (fire, air, earth, water) embodied by their traces coexist in the chöra without self-destructing. Moreover, in this way the Receptacle shares its atemporal character with eternity, but it would also be out of it, partly sensible, with its oscillatory motion, and therefore able to perform a mixing just like the Demiurge: both the chōra and the Demiurge are in the metaxu, they embody a form of instantaneous agency that mixes elements and orders the world. In both cases, the result is a transition from paradigms to a geometrized and sensible world. In the case of the demiurgic agency, this is the result of a teleological agency and it is accompanied with joy. In the case of the chorra, it is the purely mechanical shaking that orders the elements, and it is the complex interaction of the parts that constitutes the geometry of the whole physical world. I shall investigate in another paper the further implications of my reading on the Receptacle and the demiurgic agency, but I would like to leave the reader now with a clearer sense of the relevance of Plato's multifaceted notion of atemporality and of instantaneity in particular.

24 The choice of this metaphor recalls the Eleusinian Mysteries, in which a corn grain was shown to the adepts and the ceremony was accompanied by sounds produced by bronzed plates, similar to gongs. These products were artisanal artefacts that pertained to the mythos of demiurges, see Blakely 2006. I think it is worth mentioning these aspects in order to grasp the symbolic import of the chōra and Plato's allusion to esoteric wisdom as a potentially different way of dealing with fundamental questions. Indeed, the adepts of the Great Mysteries did not actively learn the secrets of the cosmos (it was not a matter of mathēsis), but rather had to learn to feel, pathein, to use emotions that could lead them to a different type of wisdom and knowledge. 


\subsection{Closing Remarks}

In this contribution, I emphasized how time is not fundamental but coderivative, together with the world's structure, from the combination of both the circular motion of the sphere where the fixed stars rest and the variable motion of the orthogonal plane of planetary orbits. Time, together with space, is identified as the only possible means of measuring this three-dimensional world and in its essential definition, time is something that presupposes the existence of the perfection or the paradigm that it imitates, i.e., eternity. Furthermore, I have shown how time is portrayed as something that apparently flows as a fixed unit throughout all of number series. However, as shown in sections 6.2-6.3, a clearer account of temporality emerges once we focus on its opposite, atemporality. We can certainly appreciate the fact that Plato's concept of atemporality is in turn far richer than normally expected. Indeed, eternity is atemporal, like the instant, but, just like time, it seems to have a peculiar metron. This is something that cannot hold for the instant. The measure of the Being and eternity is the "Now," an unbounded presentness. The "Now" is not a dimension of the physical world, because it is out of the time series, which in turn imitates eternity and has unit measures to distinguish its parts. The instant, on the contrary, cannot be divided and cannot be measured. The latter constitutes a specific form of atemporality that makes generation possible and thinkable without contradiction. If the Demiurge and the chorra are two fundamental pillars guaranteeing the dynamics of the constituents of the world, they also enable the transition from sempiternity to the sensible world. Albeit in different ways, they nevertheless share this very specific form of atemporality and "inhabit" the metaxu.

\section{Acknowledgement}

I am indebted to Daniel Vázquez and Viktor Ilievski for fruitful discussions on the earlier draft of this paper. This research is part of PROTEUs "Paradoxes and Metaphors of Time in Early Universe(s)", a project that has received funding from the European Research Council (ERC) under the Horizon 2020 research and innovation programme (Grant agreement No. 758145). 


\section{References}

Allen, B. M. 1947. “The Early Roman Calendar." The Classical Journal 43, no. 3: 163-68.

Blakely, S. 2006. Myth, Ritual and Metallurgy in Ancient Greece and Recent Africa. Cambridge: Cambridge University Press.

Bluck, R. S. 196o. "The Second Platonic Epistle." Phronesis 5, no. 2:140-51.

Brisson, L. 1970. "L'Instant, le temps, et l'éternité dans le Parménide (155e-157b) de Platon." Dialogue: Canadian Philosophical Review/Revue canadienne de philosophie 9, no. 3: 389-96.

Brisson, L. 1977. 'La question du statut de 'Parm.' 155e4-157b5 dans la seconde partie du 'Parménide' de Platon examinée à l'aide de l'informatique et de la statistique lexicale." In Recherches sur la tradition platonicienne (Platon, Aristote, Proclus, Damascius), edited by J. Bertier, L. Brisson, J. Combes and J. Trouillard, 9-29. Paris: Vrin.

Brisson, L. 200o. Lectures de Platon. Paris: Vrin.

Brisson, L. 2012. "Chapter 18 of the De Communi Mathematica Scientia Translation and Commentary." In Iamblichus and the Foundations of Late Platonism, edited by E. V. Afonasin, J. M. Dillon and J. Finamore, 37-49. Leiden: Brill.

Brisson, L. 2016. "The Intellect and the Cosmos: The Demiurge in the Timaeus." Methodos. Savoirs et textes 16: 1-17.

Broadie, S. 2012. Nature and Divinity in Plato's Timaeus, Cambridge: Cambridge University Press.

Cherniss, Harold F. 1944. Aristotle's Criticism of Plato and the Academy. Baltimore: Johns Hopkins University Press.

Cornelli, G. 2010. “Una Metafisica Pitagorica nel 'Filebo'?". Méthexis 23: 35-52.

Cornford,F.M., trans.1952.Plato's Cosmology:TheTimaeusofPlato.Indianapolis: Hackett. Finamore, John, and John Dillon. 2002. Iamblichus' De Anima: Text, Translation, and Commentary. Leiden: Brill.

Freeth, T., Higgon, D., Dacanalis, A., MacDonald, L., Georgakopoulou, M., \& Wojcik. A Model of the Cosmos in the ancient Greek Antikythera Mechanism. Sci Rep 11, 5821 (2021). https://doi.org/10.1038/s41598-021-84310-w.

Gregory, Andrew. 200o. Plato's Philosophy of Science. London: Duckworth.

Hannah, R. 2005. Greek and Roman Calendars: Constructions of Time in the Classical World. London: Duckworth.

Hannah, R. 2017. "The Intellectual Background of the Antikythera Mechanism." In The Construction of Time in Antiquity: Ritual, Art, and Identity, edited by J. Ben-Dov and L. Doering, 83-96. Cambridge: Cambridge University Press.

Johansen, Thomas Kjeller. 2008. "The Timaeus on the Principles of Cosmology." In The Oxford Handbook of Plato, edited by G. Fine, 287-307. Oxford: Oxford University Press. 
Johansen, Thomas Kjeller. 2014. "Why the Cosmos Needs a Craftsman: Plato, Timaeus 27d5-29b1." Phronesis 59, no. 4: 297-320.

Kalligas, P. 2016. "Platonic Astronomy and the Development of Ancient Sphairopoiia." Rhizomata 4, no. 2: 176-20o. doi: https://doi.org/10.1515/rhiz-2016-oo1o. Accessed on $11 / 10 / 2020$.

Kolb, David A. 1974. "Time and the Timeless in Greek Thought." Philosophy East and West 24, no. 2: 137-43.

McHugh, M. 2019. "Plato's Timaeus and Time." In Plato at Syracuse: Essays on Plato in Western Greece with a new translation of the Seventh Letter by Jonah Radding, edited by H. Reid and M. Ralkowski, 167-84. Sioux City: Parnassos Press-Fonte Aretusa.

Perrin, B., trans. 1914. Plutarch: Plutarch's Lives. Cambridge, MA.: Harvard University Press.

Pritchett, W. K., and B. L. Van der Waerden. 1961. "Thucididean Time-Reckoning and Euctemon's Seasonal Calendar." Bulletin de correspondance hellénique 85, no. 1: $17-5^{2}$.

Sallis, John. 1999. Chorology: On Beginning in Plato's Timaeus. Bloomington: Indiana University Press.

Sattler, B.M., 2019. Time and Space in Plato's Parmenides. Études platoniciennes, (15). DO I : https://doi.org/10.400o/etudesplatoniciennes.1717Sedley, D. 2007. Creationism and its Critics in Antiquity. Berkeley: University of California Press.

Sorabji, Richard. 1983. Time, Creation, and the Continuum: Theories in Antiquity and the Early Middle Ages. Chicago: University of Chicago Press.

Thein, K. 2020. "Planets and Time: A Timaean Puzzle". In Plato's Timaeus. Leiden, The Netherlands: Brill. doi: https://doi.org/10.1163/9789004437081_oo6.

Vlastos, G. 1965. "Creation in the Timaeus: Is It a Fiction?" In Studies in Plato's Metaphysics, edited by Reginald E. Allen, 401-19. London: Routledge and Kegan Paul. Von Leyden, W. 1964. "Time, Number, and Eternity in Plato and Aristotle" The Philosophical Quarterly 14, no. 54: 35-52.

Whittaker, J. 1968. “The 'Eternity' of the Platonic Forms." Phronesis 13, nos. 1-2: 131-44. Zhmud, L., 2013. Pythagorean Number Doctrine in the Academy. G. Cornelli, $R$. McKirahan, \& C. Macris, Edits.) ONPYTHAGOREANISM(STUDIA PRESOCRATICA), 5 , pp.323-345. 